Research Article

\title{
Overcoming Concreting Problems of Rigid Pavements using Knowledge-Based System
}

\author{
Ahmed Mancy Mosa*,, Lubna Abdulrahman Salem ${ }^{2}$, Qais Sahib Banyhussan ${ }^{3}$ \\ ${ }^{1}$ Civil Engineering Department, AL-Mansour University College, Baghdad, Iraq \\ ${ }^{2}$ Computer Technology Engineering Department, AL-Mansour University College, Baghdad, Iraq \\ ${ }^{3}$ Highway and Transportation Engineering Department, College of Engineering, Mustansiriyah University
}

\section{Keywords}

Concreting, Rigid Pavements, Knowledge-Based system, Solutions, Causes, Preventive actions.

\begin{abstract}
Highway engineers encounter numerous problems during rigid pavement concreting. Thus, deciding on appropriate controlling measures is a crucial task. These problems affect the quality of pavements and increase initial cost. Experts can control them, but novices cannot. Therefore, this study describes the development of a novel knowledge-based system to control concreting problems of rigid pavements. The knowledge that includes problems encountered in the domain, their causes, preventive actions, solutions, and their effects was acquired from the experts by different methods and was presented in a classified format. The calcified knowledge was transferred into rules and coded in software by using Visual Basic. The system was tested by different users involved in highway engineering, including experts and novice engineers. The mean values of the overall system evaluation by the four types of users based on the 5-point Likert scale were 4 and 4.5 respectively. The developed system can be used to help highway engineers overcome the problems during concreting of rigid highway pavements, identify their causes, preventive actions, and effects on the construction process. It can also be used to help the experts formulate decisions quickly. The system facilitates decision making of domain experts by reducing unnecessary inputs, performing quick calculations, and providing classified recommendations. In addition, it can be used as an instructional tool for pavement engineers or highway engineering students, to interchange the expertise among the experts, and to transfer expertise to the next generation of engineers.
\end{abstract}

\section{Introduction}

The development of a highway system, which is a major infrastructure element [1,2,3], is important in improving a country's economy [4,5,6,7]. Rapid urbanization has become an increasingly problematic feature of economic development $[8,9]$. Urbanization and a growing population require sufficient facilities for transporting goods and people $[10,11]$. Highway networks are the main facility in transportation systems $[12,13]$. Therefore, the construction of highquality, durable, and smooth new highways is necessary $[1,4,5]$ to connect city centers with newly expanding districts and other locations. Pavements can be considered the most critical part of highway construction [14]. Pavement construction requires team efforts [15]. Success in construction can be achieved by applying these efforts intelligently at a reasonable price within a given timeframe $[7,11]$. However, highway engineers encounter several problems during the construction of rigid pavements $[16,17,18]$. Among the problems that occur during the construction of rigid pavements, those that occur during concreting are more critical as their occurrence leads to more complex problems. Therefore, the highway engineer must decide appropriate controlling measures, suggest effective solutions, identify causes, specify preventive actions to prevent recurrent problems, and anticipate the effects of uncontrolled problems. In addition, the adoption of preventive action for these problems prior to their occurrence is very helpful. Experts can control and solve these problems using their tacit knowledge $[19,20,21]$ because diagnosing these problems and suggesting suitable solutions require extensive engineering experience. However, novice engineers cannot yet overcome such problems [13,22]. Therefore, the development of a knowledge-based system in this domain is necessary to help engineers overcome domain problems, suggest suitable solutions, avoid the causes of the

problems, and prevent similar problems from occurrence in other parts of the project. Several knowledge-based systems were developed in transportation engineering domains such as transportation management, traffic control, highway project management, highway geometric design, and management of rigid and flexible pavements. Pavement management involves structural design, material selection, and maintenance and rehabilitation [6,23,24,25,26]. However, a research gap exists in the domain of rigid pavement construction and the problems therein, as this domain is not covered by a knowledge-based system. Therefore, this study aims to develop a novel advisory knowledge-based system to overcome concreting problems of rigid pavements. The proposed system contains a knowledge base of study domain problems, their description, solutions, causes, preventive actions to avoid their recurrence, and their effects if not controlled.

\section{System Building}

\subsection{Knowledge Acquisition}

The knowledge was extracted from multiple sources of expertise in the field of rigid pavement construction. Using multiple sources ensures an acceptable agreement on ideas and procedures. The advantages of relying on multiple sources include the exclusion of bias towards a single view, less reliance on a single domain expert for knowledge elicitation, and representation of the real situation in the field in case of conflicting views in which further research is often 
required. This stage mainly involved two steps: written knowledge acquisition and human expertise acquisition. The first step was implemented by detailed analysis of textbooks, manuals, guides, research publications, and any other written source. This acquired knowledge was used as the core knowledge in the development of the initial knowledge base. Knowledge obtained in this step was repeatedly refined by extensive analysis to specify the boundaries of the study domain as well as to understand descriptions and causes, preventive actions that can be adopted to avoid the occurrence of the problems, application of an immediate solution, and possible consequences if not prevented or treated. The second step was implemented through four sub-steps: unstructured interviews, structured interviews, questionnaire forms, and focus interviews.

After the collection of filled questionnaires, experts 1, 2, and 3 were interviewed again to clarify their comments and to focus on specific details in their solutions.

\subsection{Classification of Domain Problems}

Through extensive review and repeated analysis of the acquired knowledge, the domain problems were identified and classified depending on their forms, locations, effects, and other common features. In doing so, inspectors can visually diagnose a problem or via tests and measurement results. In addition, the description of problems, their likely causes, preventive actions, instantaneous solutions, and possible effects if they remained uncontrolled are stated. Repeated classification stages were discussed with three experts (1, 2, and 3 in Table 1) for modification. The three experts reviewed the final classification during focus interviews and agreed that it represented their knowledge accurately. Figure 1 illustrates the classification diagram of the problems. The problems were identified depending on their characteristics, which could be visually diagnosed according to their appearance or through measurements and tests. The name of each problem summarizes its description. Experts can easily note such problems and quickly come up with solutions, whereas novice engineers cannot.

Table 1 Methods adopted in human expertise acquisition

\begin{tabular}{ccccc}
\hline$E$ & UI & SI & Q & FI \\
1 & yes & yes & yes & yes \\
2 & yes & yes & yes & yes \\
3 & yes & yes & yes & yes \\
4 & yes & yes & no & no \\
5 & yes & yes & no & no \\
6 & no & no & yes & no \\
\hline
\end{tabular}

E: Expert No:; UI: Unstructured interviews; SI:

Structured interviews; Q: Questionnaire; FI: Focus

interviews(after questionnaire completion)

\subsection{Knowledge Representation}

To use the acquired knowledge, the knowledge is represented symbolically to be manipulated in an automated manner by knowledge-based system reasoning. Therefore, the implementation environment of the system must be selected prior to the selection of the knowledge representation method. In this study, Visual Basic was selected to develop the proposed system as it is an effective and flexible tool to develop such systems. The domain knowledge was represented in the form of rules. More than 250 rules were created and embedded within the source code of the system. When problems arise, experts need to collect information regarding the issue and then make a decision. Therefore, a forward chaining inference engine (which is data driven) is suitable for knowledge representation. This procedure works in accordance with the facts in the knowledge base towards the goal or conclusion. Reasoning originates from the given information and then continues forward with it. This approach depends on IF-THEN relationships. That is, if the IF condition is matched in a rule, the action in its THEN part shall be applied. This process can be modeled as IF (condition) THEN (conclusion). Two or more rules can be logically connected by connection terms AND, OR, and ELSE to form the combined rule. The connection of combined rules can produce composite rules. The classified knowledge, which represents the core of the proposed system, was prepared in the form of rules coded in a computer environment.

The following example can clarify the representation of the knowledge by the rules:

[IF (retarder was used in the concrete) AND $\left(32{ }^{\circ} \mathrm{C}>\right.$ concrete temperature $\left.>27^{\circ} \mathrm{C}\right)$ AND $\left(32^{\circ} \mathrm{C}>\right.$ air temperature $\left.\left.>27{ }^{\circ} \mathrm{C}\right)\right]$ OR

[IF (no admixtures were used in concrete) AND (concrete temperature $<27^{\circ} \mathrm{C}$ ) AND (air temperature $<27^{\circ} \mathrm{C}$ ) AND (the concrete is hauled by an agitating truck) AND (agitator was on dynamic mode during hauling)] THEN (maximum allowable time for hauling concrete $=90$ minutes)

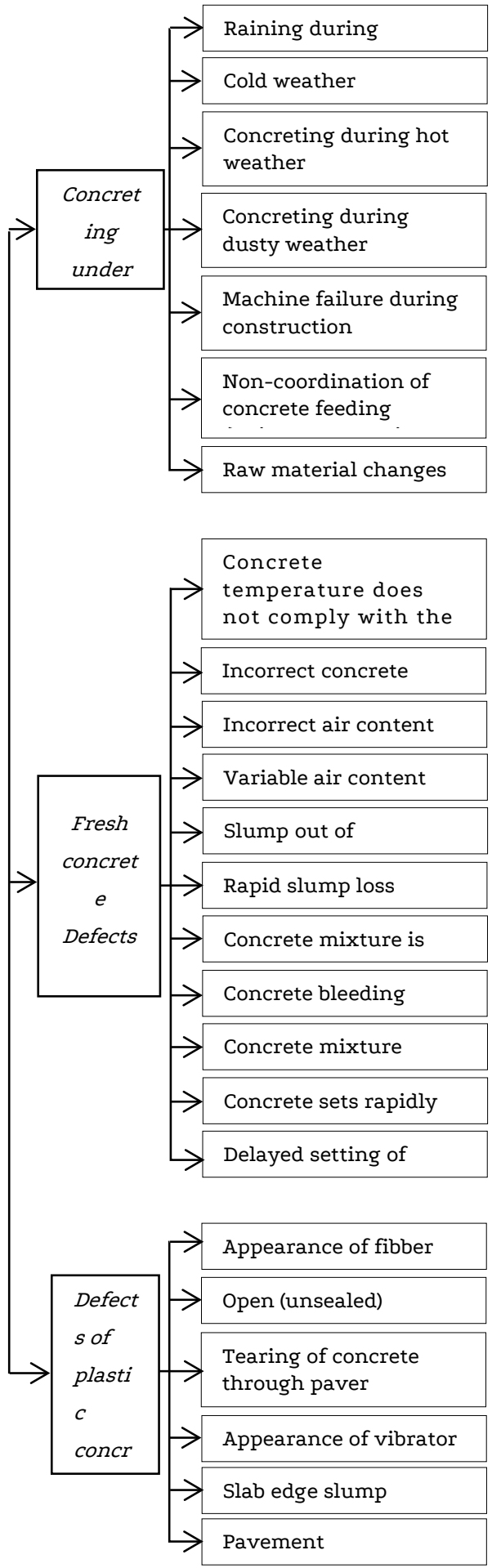

Figure 1. Classification of Domain Problems 


\section{The Structure of the System}

This section describes the structure of the system, which consists of a graphical user interface, working memory, inference engine, and knowledge base. The components of the system work jointly to provide the user with fast, clear, and efficient recommendations. The graphical interface is the only component that can be viewed by the user. Through the graphical interface, the user can input data and obtain recommendations. User inputs are contained in working memory via the interface. The inference engine uses inputs via the working memory as well as searches the rules in the knowledge base to match the problem description and provide recommendations.

User interface has a special importance as it is the interface between the user and the system. The user communicates with the system via this interface. Generally, the system obtains the information needed to solve a particular problem by asking the user to answer questions or prompting the user to provide relevant information in a preformatted manner via the interface. The user interface was designed to collect the information and present the whole system without restricting the overall performance. It was designed with a good graphic to reduce the required learning time and the number of mistakes made by first-time users.

Regardless of how well the knowledge base is organized or how effective the system's performance is, the quality of user interface design alone may determine the fate of the knowledge-based system.
The system was built by creating a new project under the Visual Basic environment. Visual Basic creates at least one form with each project. Each form includes the interface window (screen) and a code window. Figures 2 and 3 illustrate examples of the interface window (screen) and the code window respectively. The interface windows were designed to be clear, user-friendly, and interactive. The interface window includes a number of components or controls (each represents a tool) such as frames, labels, text boxes, images, option buttons (radio buttons), checkboxes, command buttons, windows media player, adobe acrobat reader, combo boxes, and message boxes. Each control was designed to perform a specific function in the form. Forms and controls are called objects. Visual Basic was utilized to design clear interface windows by using a variety of colors for background and texts. Changes in colors, fonts, and other visual effects were used to bring the user's attention to some points. Fig. 2 shows the test machine used in this research.

The inference engine is the control mechanism that organizes the problem data and searches the knowledge base for applicable rules. The inference engine reaches a conclusion by matching appropriate rules under a set of specific facts.

Basically, the inference engine operates as follows: IF the premise of a rule is true, THEN the conclusion is true. Figure 4 provides an example of how the inference engine works.

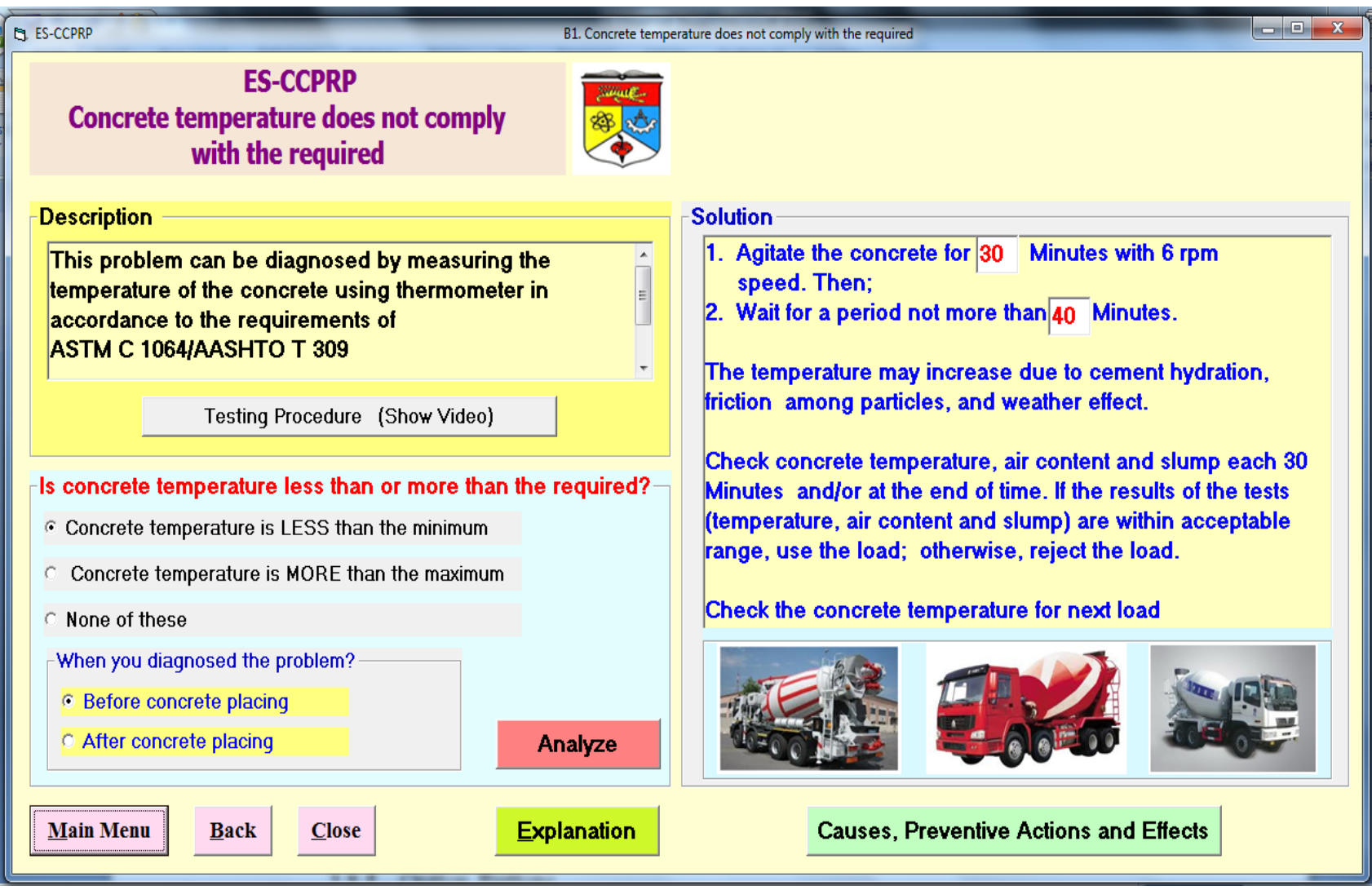

Figure 2. Example of user interface window 


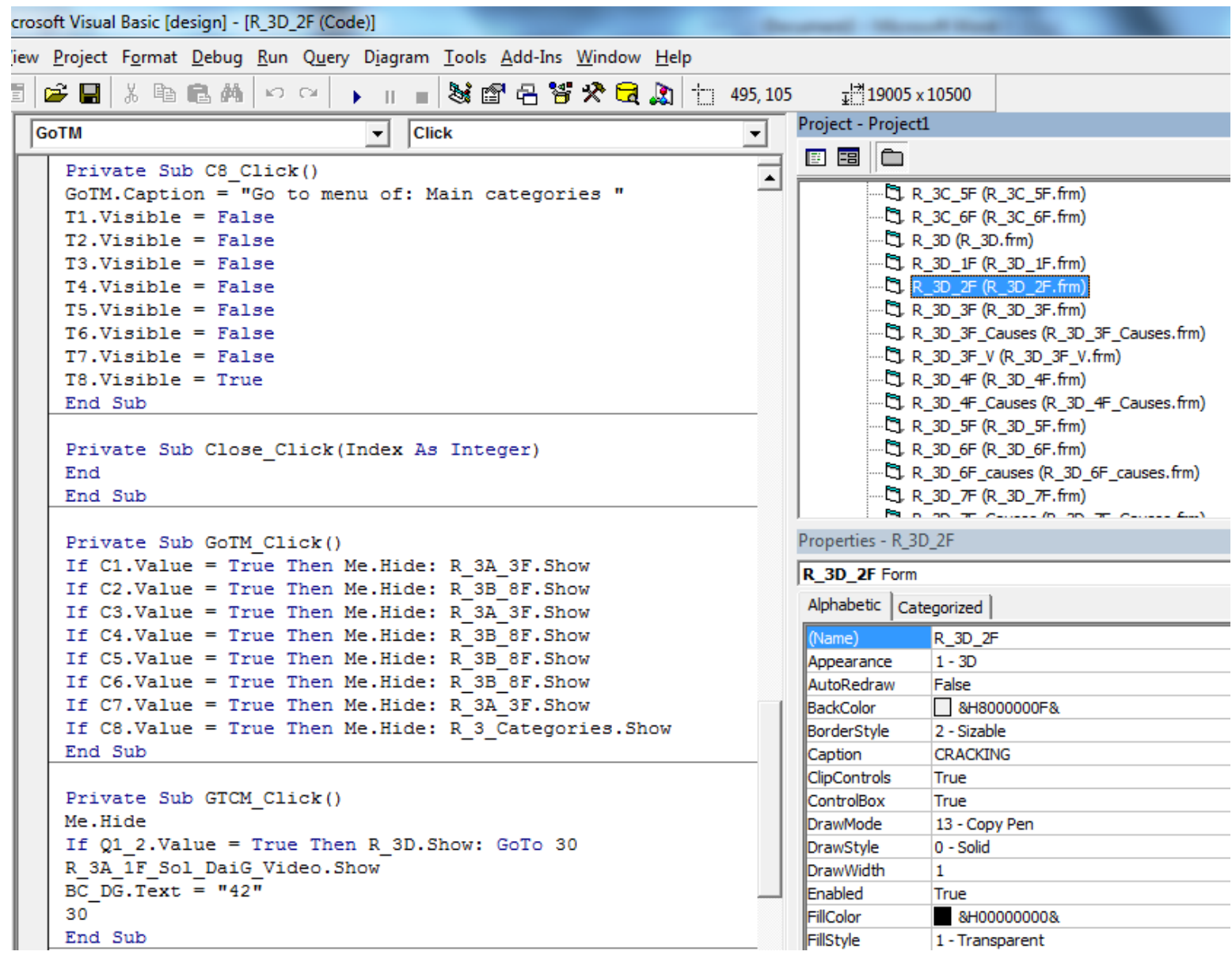

Figure 3. Example of code window

\section{System Testing}

A questionnaire survey was designed to test the satisfaction of 4 experts in rigid pavements with the system. The rigid pavement experts evaluated the system by using the questionnaire described in Table 2 . The evaluation reflects their satisfaction through their high ratings (more than 3 ). The satisfaction of experts indicates that they positively evaluated the user interface; this result also verifies the system. Table 2 summarizes the testing and evaluation of the system by the domain experts.

Another questionnaire was designed to test the satisfaction of 10 novice highway engineers with the system. The highway engineers evaluated the system by using the questionnaire described in Table 3. The evaluation reflects the satisfaction of the users through their high ratings (more than 3). The satisfaction of the participants indicates that they positively evaluated the user interface; this result also verifies the system.
Table 2 Evaluation results of the system by 4 domain experts

\begin{tabular}{|c|c|c|c|c|c|c|}
\hline Questions & & & & Score & & \\
\hline & 1 & 2 & 3 & 4 & 5 & $A v^{1}$ \\
\hline The system is easy to use & & & & $\begin{array}{l}\checkmark \checkmark \checkmark \\
\checkmark\end{array}$ & & 4.00 \\
\hline The system runs quickly & & & & & $\begin{array}{c}\checkmark \checkmark \checkmark \\
\checkmark\end{array}$ & 5.00 \\
\hline $\begin{array}{l}\text { The user interface is user- } \\
\text { friendly }\end{array}$ & & & $\checkmark$ & $\checkmark \checkmark$ & $\checkmark$ & 4.00 \\
\hline The questions are helpful & & & & $\checkmark \checkmark$ & $\checkmark \checkmark$ & 4.50 \\
\hline The questions are clear & & & & $\checkmark \checkmark$ & $\checkmark \checkmark$ & 4.50 \\
\hline The terms are clear & & & & $\checkmark \checkmark$ & $\checkmark \checkmark$ & 4.50 \\
\hline $\begin{array}{l}\text { Presentation of results is } \\
\text { clear }\end{array}$ & & & & $\checkmark \checkmark \checkmark$ & $\checkmark$ & 4.25 \\
\hline $\begin{array}{l}\text { Presentation of results is } \\
\text { complete }\end{array}$ & & & & $\checkmark \checkmark$ & $\checkmark \checkmark$ & 4.50 \\
\hline $\begin{array}{l}\text { Obtaining explanations } \\
\text { from system is easy }\end{array}$ & & & & $\checkmark \checkmark \checkmark$ & $\checkmark$ & 4.25 \\
\hline $\begin{array}{l}\text { The system is helpful to } \\
\text { provide solutions }\end{array}$ & & & & $\begin{array}{c}\checkmark \checkmark \checkmark \\
\checkmark\end{array}$ & & 4.00 \\
\hline $\begin{array}{l}\text { The system is helpful to } \\
\text { specify the causes of } \\
\text { problems }\end{array}$ & & & & $\checkmark$ & $\checkmark \checkmark \checkmark$ & 4.75 \\
\hline $\begin{array}{l}\text { The system is helpful to } \\
\text { adopt preventive actions }\end{array}$ & & & & $\checkmark$ & $\checkmark \checkmark \checkmark$ & 4.75 \\
\hline $\begin{array}{l}\text { The system is helpful to } \\
\text { specify effects of } \\
\text { problems }\end{array}$ & & & & $\checkmark$ & $\checkmark \checkmark \checkmark$ & 4.75 \\
\hline $\begin{array}{l}\text { The explanations are } \\
\text { useful }\end{array}$ & & & $\checkmark$ & $\checkmark$ & $\checkmark \checkmark$ & 4.25 \\
\hline $\begin{array}{l}\text { Generally, I am satisfied } \\
\text { with the system }\end{array}$ & & & $\checkmark$ & $\checkmark \checkmark$ & $\checkmark$ & 4.00 \\
\hline
\end{tabular}


Table 3 Evaluation results of the system by highway engineers

\begin{tabular}{|c|c|c|c|c|c|c|}
\hline & & & & Scores & & \\
\hline Questions & 1 & 2 & 3 & 4 & 5 & $A v^{1}$ \\
\hline $\begin{array}{l}\text { The system is } \\
\text { easy to use }\end{array}$ & & & $\checkmark \checkmark \checkmark$ & $\begin{array}{l}\checkmark \checkmark \checkmark \\
\checkmark \checkmark \checkmark \checkmark\end{array}$ & & 3.7 \\
\hline $\begin{array}{l}\text { The system } \\
\text { runs quickly }\end{array}$ & & & & & $\begin{array}{l}\checkmark \checkmark \checkmark \checkmark \checkmark \\
\checkmark \checkmark \checkmark \checkmark \checkmark\end{array}$ & 5.0 \\
\hline $\begin{array}{l}\text { The user } \\
\text { interface is } \\
\text { user-friendly }\end{array}$ & & & $\checkmark \checkmark$ & $\checkmark \checkmark \checkmark \checkmark$ & $\checkmark \checkmark \checkmark \checkmark$ & 4.2 \\
\hline $\begin{array}{l}\text { The questions } \\
\text { are helpful }\end{array}$ & & & & $\checkmark \checkmark \checkmark \checkmark \checkmark$ & $\checkmark \checkmark \checkmark \checkmark \checkmark$ & 4.5 \\
\hline $\begin{array}{l}\text { The questions } \\
\text { are clear }\end{array}$ & & & & $\checkmark \checkmark \checkmark \checkmark \checkmark$ & $\checkmark \checkmark \checkmark \checkmark \checkmark$ & 4.5 \\
\hline $\begin{array}{l}\text { The terms are } \\
\text { clear }\end{array}$ & & & $\checkmark \checkmark$ & $\begin{array}{l}\checkmark \checkmark \checkmark \checkmark \\
\checkmark \checkmark \checkmark \checkmark\end{array}$ & & 3.8 \\
\hline $\begin{array}{l}\text { Presentation of } \\
\text { results is clear } \\
\text { Obtaining an }\end{array}$ & & & $\checkmark$ & $\begin{array}{l}\checkmark \checkmark \checkmark \checkmark \\
\checkmark \checkmark \checkmark\end{array}$ & $\checkmark \checkmark$ & 4.1 \\
\hline $\begin{array}{l}\text { explanation } \\
\text { from the } \\
\text { system is easy }\end{array}$ & & & $\checkmark$ & $\checkmark \checkmark \checkmark \checkmark \checkmark$ & $\checkmark \checkmark \checkmark \checkmark$ & 4.3 \\
\hline $\begin{array}{l}\text { Generally, I am } \\
\text { satisfied with } \\
\text { The system }\end{array}$ & & & $\checkmark$ & $\checkmark \checkmark \checkmark \checkmark$ & $\checkmark \checkmark \checkmark \checkmark \checkmark$ & 4.5 \\
\hline
\end{tabular}

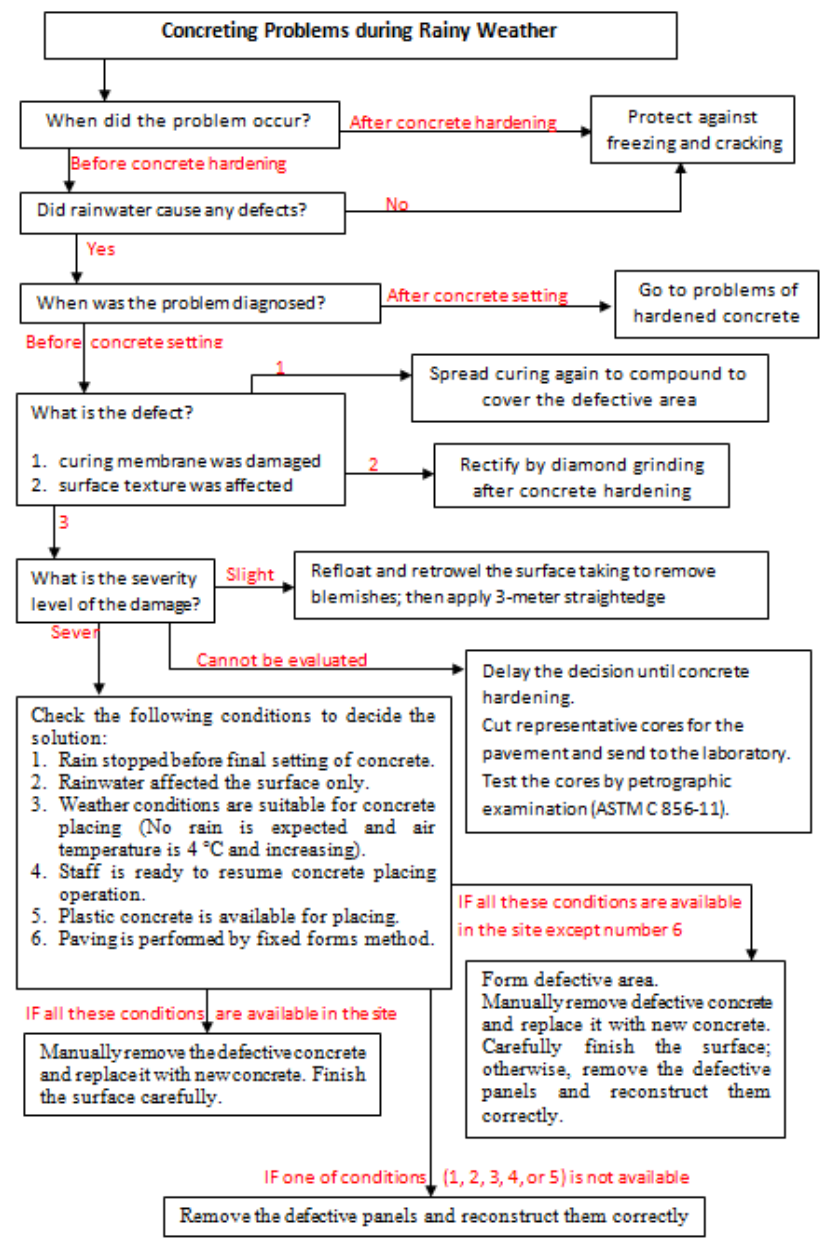

Figure 4. An example of inference engine work

\section{Conclusions}

A novel system was constructed by computerization of the acquired knowledge using Visual Basic programming language. It involves sophisticated knowledge to perform the following functions:

- As a knowledge-based system to help highway engineers overcome problems during concreting of rigid highway pavements, identify their causes, preventive actions, and effects on the construction process, pavement quality, and its future conditions. A simple graphical user interface was designed for the system to simplify the user's task.

- As a system to help the experts formulate decisions quickly. The system facilitates decision making of domain experts by reducing unnecessary inputs, performing quick calculations, and providing classified recommendations.

- As an instructional tool for pavement engineers or civil/highway engineering students. They can learn more about the domain through repeated use of the system.

- As a tool for expertise interchange among experts.

- As a tool to transfer expertise to the next generation of engineers.

- As a tool for archiving primary knowledge and human expertise in classified form available to all engineers in the study domain.

- As a foundation for the development of other highway systems.

\section{Declaration of Conflict of Interests}

The authors declare that there is no conflict of interest. They have no known competing financial interests or personal relationships that could have appeared to influence the work reported in this paper.

\section{References}

[1.] Salem LA, Taher AH, Mosa AM, Banyhussan QS (2020) Chemical influence of nano-magnesium-oxide on properties of soft subgrade soil. Periodicals of Engineering and Natural Sciences 8: 533-541.

[2.] Mohammed AA, Ambak K, Mosa AM, Syamsunur D (2018) Classification of Traffic Accident Prediction Models: A Review Paper. International Journal of Advances in Science Engineering and Technology 6: 35-38.

[3.] Mohammed AA, Ambak K, Mosa AM, Syamsunur D (2018) Traffic Accidents in Iraq: An Analytical Study. Journal of Advanced Research in Civil and Environmental Engineering 5: 1-13.

[4.] Mosa AM, Salem LA, Waryosh WA (2020) New Admixture for Foamed Warm Mix Asphalt: A Comparative Study. Iranian Journal of Science and Technology, Transactions of Civil Engineering 44: 649-660.

[5.] Banyhussan QS, Tayh SA, Mosa AM. Economic and Environmental Assessments for Constructing New Roads: Case Study of Al-Muthanna Highway in Baghdad City. Proceedings of AICCE'19; 2020; Cham. Springer International Publishing. pp. 525-546.

[6.] Mosa AM (2017) Modification of Hot Mix Asphalt Using Polyethylene Therephthalate (PET) Waste Bottles. SUST Journal of Engineering and Computer Sciences 18: 62-73.

[7.] Mosa AM, Taher AH, Al-Jaberi LA (2017) Improvement of poor subgrade soils using cement kiln dust. Case Studies in Construction Materials 7: 138-143.

[8.] Mohammed AA, Ambak K, Mosa AM, Syamsunur D (2019) Expert System in Engineering Transportation: A Review. Journal of Engineering Science and Technology 14: 229-252.

[9.] Taher AH, Salem LA, Mosa AM (2018) Aerobic and Anaerobic Treatment for Greywater Using Large Scale Model. International Journal of Civil Engineering and Technology 9: 842-849. 
[10.] Mohammed AA, Ambak K, Mosa AM, Syamsunur D (2019) A Review of the Traffic Accidents and Related Practices Worldwide. The Open Transportation Journal 13: 65-83.

[11.] Hatem MK, Mosa AM, Al-Dahlaki MH (2018) Software for Line of Balance in Projects of Highways. Journal of Engineering and Sustainable Development 22: 119-130.

[12.] Mosa AM (2017) Modification of Subgrade Properties Using Waste Material. Applied Research Journal 3: 160-166.

[13.] Mosa AM, Atiq R, Raihantaha M, Ismail A (2011) Classification of construction problems in rigid highway pavements. Australian Journal of Basic and Applied Sciences 5: 378-395.

[14.] Choi J (2011) Quantifying the effects of interference for an alternative method of construction productivity estimation. KSCE Journal of Civil Engineering 15: 761-769.

[15.] Mosa AM (2017) Influence of Nano and Ordinary Particles on Properties of Subgrade: a Comparative Study. Journal of Engineering Sciences 45: 411-421.

[16.] Mosa AM (2017) Neural Network for Flexible Pavements Maintenance and Rehabilitation. Applied Research Journal 3: 114-129.

[17.] Mosa AM, Ismail NN, Yusoff NIM, Mubaraki MA, Memon NA, et al. (2015) An expert system to remedy concrete imperfections and their effects on rigid pavements. Jurnal Teknologi 76: 105-119.

[18.] Mosa AM, Rahmat RAOK, Ismail A, Taha MR (2013) Expert System to Control Construction Problems in Flexible Pavements. Computer-Aided Civil and Infrastructure Engineering 28: 307323.

[19.] Miller S, Huerne H, Dorée A. The asphalt paving process: plans for action research. In: Atkin B, Borgbrant J, editors; 2007 14th-15th June 2007; Luleå, Sweden. Luleå University of Technology Department of Civil and Environmental Engineering. pp. 37-46.

[20.] Mosa AM, Taha MR, Ismail A, Rahmat RAOK (2013) An Educational Knowledge-based System For Civil Engineering

\section{How to Cite This Article}

Mosa, A., Salem, L., and Banyhussan, Q., Overcoming Concreting Problems of Rigid Pavements using Knowledge-Based System, Civil Engineering Beyond Limits, 3 (2021), 12-17.

https://doi.org/10.36937/cebel.2021.003.003
Students in Cement Concrete Construction Problems. Procedia Social and Behavioral Sciences 102: 311-319.

[21.] Mosa AM, Taha MR, Ismail A, Rahmat RAOK (2013) A diagnostic expert system to overcome construction problems in rigid highway pavement. Journal of Civil Engineering and Management 19: 846-861.

[22.] Mosa AM, Atiq R, Raihantaha M, Ismail A (2011) A knowledge base system to control construction problems in rigid highway pavements. Australian Journal of Basic and Applied Sciences 5: 1126-1136.

[23.] Taher AH, Al-Jaberi LA, Mosa AM (2018) Artificial Neural Network for Mix Proportioning Optimization of Reactive Powder Concrete. Journal of Theoretical and Applied Information Technology 96: 7684-7700.

[24.] Salem LA, Taher AH, Mosa AM (2018) Enhancement of Subgrade Properties Using Magnesium Oxide for Pavement Construction. International Journal of Engineering \& Technology 7: 321-324.

[25.] Mosa A, Jawadb I, Salema L (2018) Modification of the Properties of Warm Mix Asphalt Using Recycled Plastic Bottles. International Journal of Engineering 31: 1514-1520.

[26.] Al-Dahlaki MH, Mosa MKHAM (2016) Inter-Particle Pressure as influenced by Physicochemical Parameters on Microscale of Saturated Heavy Clay. Civil and Environmental Research 8: 8696.

[27.] Ma Z, Shao C, Ma S, Ye Z (2011) Constructing road safety performance indicators using fuzzy delphi method and grey delphi method. Expert Systems with Applications 38: 1509-1514.

[28.] Rezaei J, Ortt R, Scholten V (2011) Measuring entrepreneurship: Expert-based vs. data-based methodologies. Expert Systems with Applications. 